\title{
Histopathological Findings of 100 cases of Abnormal Uterine Bleeding and their Correlation with FIGO Classification
}

\author{
KAMRUN NAHAR ${ }^{1}$, SURAIYA APSARA ${ }^{2}$, LUNA FARHANA HOQUE ${ }^{3}$, HOSNE ARA BABY $^{4}$
}

\begin{abstract}
:
Abnormal uterine bleeding(AUB) is one of the most common gynaecological problems encountered in clinical practice. The PALM-COEIN classification for causes of AUB was proposed by the International Federation of Gynaecology and Obstetrics (FIGO) in 2011, which has gradually been applied in Bangladesh for the diagnosis of AUB.

Objective: the objective of this study was to evaluate the prevalence of chronic AUB according to FIGO classification in reproductive age women, carry out histopathological study and analyze it's clinicopathological pattern.

Material and methods: this descriptive cross sectional study was carried out among 100 women of reproductive age (20-49 years) who presented with abnormal uterine bleeding (AUB) in the department of obstetrics and gynaecology of Dhaka Medical College Hospital during the period of January 2012 to December 2012. Clinical diagnosis was made according to PALM-COEIN classification on the basis of history, examination and necessary investigations. Endometrial sample and hysterectomy specimen were assessed by histopathology.

Result: Thirty five (35\%) percent patients were 41-45 years. Ninety two (92\%) patients were married ,2(2\%) were unmarried and 6(6\%) were widow. Among married women $98 \%$ were fertile and $2 \%$ were subfertile. Most common presenting symptom was menorrhagia (48\%), followed by metrorrhagia (25\%) and polymenorrhoea was observed in $22 \%$ cases. Ovulatory dysfunction (AUB-O) was the most common cause of abnormal uterine bleeding among the non structural causes and it was $44 \%$. AUB-L were the most common (30\%) among the structural causes, followed by $A \cup B-A(10 \%)$ and $A \cup B-P(5 \%)$. Regarding histopathological findings most of the patients(34\%) revealed unremarkable histopathological findings. Other findings were leiomyoma $27(27 \%)$, adenomyosis $13(13 \%)$ and fibroid uterus with adenomyosis in 5(5\%) cases.
\end{abstract}

Conclusion: $A \cup B-O$ was the leading cause of abnormal uterine bleeding and histopathological evaluation correlated well with the clinical diagnosis.

Key words: Abnormal uterine bleeding, PALM -COEIN classification, Histopathology.

\section{Introduction:}

Abnormal uterine bleeding(AUB) a common gynaecological problem is defined as any bleeding from the uterus which is not normal cyclical menstruation $^{1}$. Majority of women presenting with AUB belong to reproductive age ${ }^{2}$. The prevalence of AUB in reproductive aged women internationally is estimated to be between $3 \%$ to $30 \%$ with a higher

1. Dr. Kamrun Nahar (FCPS), Associate Professor, Dept. of Obst and Gynae. Shahabuddin Medical College Hospital.

2. Dr. Suraiya Apsara, Registrar, Dept. of obst and Gynae. Shahabuddin Medical College Hospital.

3. Dr. Luna Farhana Hoque (FCPS), Registrar- Obst and Gynae. Shahabuddin Medical College Hospital.

4. Professor Dr. Hosne Ara Baby (FCPS)- Consultant Obst and Gynae. Bangladesh Specialized Hospital.

Address of Correspondence: Dr. Kamrun Nahar (FCPS), Associate Professor, Dept. of Obst and Gynae. Shahabuddin Medical College Hospital. 
incidence occurring around menarche and perimenopause ${ }^{3}$. Abnormal uterine bleeding may be excessively heavy (HMB) or unusually light and may be prolonged, frequent or random or less. It may be acute or chronic. When abnormal uterine bleeding persists more than six months it is called chronic $A_{U B}{ }^{4}$. The terminology of AUB includes the following clinical entities ${ }^{5}$ - menorrhagia, polymenorrhoea, polymenorrhagia, metrorrhagia, oligomenorrhoea, midcycle spotting.

AUB may be caused by variety of factors. The two most common causes are structural abnormalities of the reproductive system and ovular disorder ${ }^{6}$. The International Federation of Gynecology and Obstetrics (FIGO) in 2011 has approved a new classification system (PALM-COEIN) for causes of abnormal uterine bleeding in non gravid women of reproductive age ${ }^{7}$. The acronym PALM-COEIN is now being widely used for categorizing the causes of AUB.

\begin{tabular}{ll}
\hline PALM & COEIN \\
\hline Polyp( AUB-P) & $\begin{array}{l}\text { Coagulopathy ( AUB-C) } \\
\text { Ovulatory dysfunction } \\
\text { Adenomyosis ( AUB -A) }\end{array}$ \\
$\begin{array}{ll}\text { Leiomyoma ( AUB-L) } \\
\text { Malignancy and hyperplasia } \\
\text { (AUB-M) }\end{array}$ & $\begin{array}{l}\text { latrogenic (AUB-I) } \\
\text { Not yet classified (AUB -N) }\end{array}$ \\
\hline
\end{tabular}

PALM-COEIN classification: causes of abnormal uterine bleeding

The diagnosis of AUB depends on the medical history, clinical examination and investigations. Investigations like ultrasonography, pap's smear, hysteroscopy, cervical biopsy and endometrial biopsy have to be done according to history and clinical examination findings. There are several techniques available to obtain a sample for histopathology, including simple aspiration, fractional curettage, blind $D$ and $C$ (dilatation and curettage) and more recently hysteroscopic biopsies in an out patient setting ${ }^{2}$. Hysteroscopy remains the gold standard for accurate assessment of endometrial cavity ${ }^{2}$. The aetiological factors, investigation procedures and treatment modalities vary widely in three major age groups namely the pubertal age group, the reproductive age group and the perimenopausal age group. In reproductive age ovular type of bleeding is most typical. Here mostly cyclical bleeding occurs with excessive in amount or duration. Another type of ovular bleeding occurs as pre or post menstrual spotting. Anovular type of bleeding occurs in adolescent and perimenopausal age group.

Every women with AUB require rapid, safe and effective treatment for their menstrual problem. Treatment is either medical or surgical. AUB is a common reason for women to be referred to gynaecologists and is an indication for up to $25 \%$ of all gynaecological surgeries ${ }^{8}$. Surgical options include endometrial ablation, $\mathrm{D}$ and $\mathrm{C}$ (dilatation and curettage), hysteroscopy and hysterectomy. Endometrial ablation is an option for patients seeking to avoid hysterectomy ${ }^{9}$. D and $\mathrm{C}$ is both a diagnostic and a therapeutic procedure. Hysterectomy provides a definitive cure of AUB. Half of all hysterectomies in United States are performed to treat abnormal uterine bleeding $^{10}$. Hysterectomy is justified when conservative methods have failed and the bleeding seriously interferes with the wellbeing of the patient .There is good evidence to suggest that hysteroscopy in an ambulatory setting is preferred by most women, avoids complications and allows a quicker recovery time ${ }^{11,12}$. Office hysteroscopy for the diagnosis and management of AUB has developed into an easily performed procedure with minimal discomfort and significantly reduced risks and expense.

$A$ variety of obscured uterine pathology may be diagnosed pre-operatively that causes AUB. Ultimate diagnosis is only on histopathology, so every curetting material and hysterectomy specimen should be subjected to histopathological examination ${ }^{13}$.

\section{Material and methods:}

This cross sectional study was conducted in the department of obstetrics and gynaecology of Dhaka Medical College Hospital from January 2012 to December 2012. Hundred women of reproductive age who admitted with chronic AUB were studied. Women suffering from acute AUB and obstetric cause of vaginal bleeding were excluded from the study. Ethical clearance was taken from the institute and informed written consent was taken from all patients. Data was collected through direct interview on structured questionnaire. Diagnosis of AUB was based on detailed previous and present menstrual history including duration, frequency, flow and dysmenorrhoea, contraceptive history, family history of polycystic ovary syndrome (POCS), bleeding disorder, medical history, physical examination including general and pelvic examination findings. 
Laboratory assessment of haemoglobin level, leutinizing hormone, follicle stimulating hormone, prolactin, thyroid function test, beta hCG, androgen profile and pap's smear for cervical dysplasia was done. Clinical diagnosis with TVS findings and all other investigation reports were correlated and allocated to PALM-COEIN classification .Endometrial biopsy sample and hysterectomy specimen were obtained and sent for histopathology. The diagnosis was confirmed by histopathology. Clinical diagnosis was then correlated with histopathology based final diagnosis.

Statistical analysis was done in computer using software SPSS. The results were presented as frequency and percentage.

\section{Results:}

Out of one hundred cases of abnormal uterine bleeding in reproductive aged women who underwent surgery (either TAH or D and C) the commonest age group was between $41-45$ years (35\%). Ninety two percent patients were married and $2 \%$ were unmarried. Among married women $98 \%$ were fertile. Ninety five percent patients were anaemic, $14 \%$ had diabetes mellitus and $13 \%$ patients were obese (Table-I). Table -II showed $38 \%$ patients were para 5 and above. Menorrhagia was the commonest (48\%) presenting symptom followed by metrorrhagia (25\%) and polymenorrhoea (22\%)(Table-III). Fifty three percent patients were suffering from AUB for 1-3 years (Fig -1). Clinically nonstructural (COEIN) cause were diagnosed in $52 \%$ cases and structural (PALM) cause were found in $48 \%$ cases. AUB-O was the most common cause of abnormal uterine bleeding (44\%) among the nonstructural causes. AUB-L were the commonest $(30 \%)$ among the structural causes, followed by AUB-A (10\%) and AUB-P (5\%) (Table-IV). Regarding histopathology $34 \%$ cases revealed unremarkable histopathological findings. Other findings were leiomyoma $27 \%$, adenomyosis $13 \%$ and leiomyoma with adenomyosis in $5 \%$ cases (Table-V). Histopathological findings and clinical diagnosis were correlated. In AUB-O clinical diagnosis and histopathlogical diagnosis was $44 \%$ vs $32 \%$, AUB-L $30 \%$ vs $27 \%$ and AUB-P $5 \%$ vs $5 \%$.More AUB-A were diagnosed on histopathology $10 \%$ vs $13 \%$ (Table- $\mathrm{VI}$ ). Proliferative endometrium were found in $46 \%$ cases, followed by secretory endometrium in $32 \%$, endometrial hyperplasia $11 \%$ case, endometrial and cervical polyp in $6 \%$ and atrophic endometrium were found in $4 \%$ cases (Table-VIII).
Table-I

Distribution of study subjects according to clinical characteristics $(n=100)$

\begin{tabular}{lcc}
\hline Age (years) & $\begin{array}{c}\text { Number } \\
(\mathrm{n}=100)\end{array}$ & Percentage \\
\hline $20-25$ & 6 & 6 \\
$26-30$ & 8 & 8 \\
$31-35$ & 16 & 16 \\
$36-40$ & 22 & 22 \\
$41-45$ & 35 & 35 \\
$46-49$ & 13 & 13 \\
Marital status $(\mathrm{n}=100)$ & & \\
$\quad$ Married & 92 & 92 \\
$\quad$ Unmarried & 2 & 2 \\
$\quad$ widow & 6 & 6 \\
Fertility ( $\mathrm{n}=98)$ & & \\
$\quad$ Fertile & 96 & 98 \\
$\quad$ Subfertile & 2 & 2 \\
Anaemia ( $\mathrm{n}=100)$ & 95 & 95 \\
Obesity $(100)$ & 13 & 13 \\
Diabetes mellitus $(\mathrm{n}=100)$ & 14 & 14 \\
\hline
\end{tabular}

Table-II

Distribution of study subjects according to parity $(n=98)$

\begin{tabular}{lcc}
\hline No of pregnancies & $\begin{array}{c}\text { Number of } \\
\text { patients }\end{array}$ & Percentage \\
\hline Nil & 2 & 2 \\
1 & 8 & 8 \\
2 & 13 & 13.26 \\
3 & 17 & 17.34 \\
4 & 20 & 20.4 \\
5 and above & 38 & 38 \\
\hline
\end{tabular}

Table-III

Distribution of study subjects according to menstrual abnormality $(n=100)$

\begin{tabular}{lcccc}
\hline Age (years) & $\begin{array}{c}\text { Meno- } \\
\text { rrhagia }\end{array}$ & $\begin{array}{c}\text { Polymeno- } \\
\text { rrhoea }\end{array}$ & $\begin{array}{c}\text { Merto } \\
\text { rrhagia }\end{array}$ & $\begin{array}{c}\text { Hypomeno- } \\
\text { rrhoea }\end{array}$ \\
\hline $20-25$ & 2 & 2 & 2 & 0 \\
$26-30$ & 2 & 1 & 1 & 1 \\
$31-35$ & 4 & 1 & 2 & 1 \\
$36-40$ & 10 & 4 & 4 & 2 \\
$41-45$ & 18 & 5 & 8 & 1 \\
$46-49$ & 12 & 9 & 8 & 0 \\
Total (n=100) & 48 & 22 & 25 & 5 \\
\hline Percentage & 48 & 22 & 25 & 5 \\
\hline
\end{tabular}




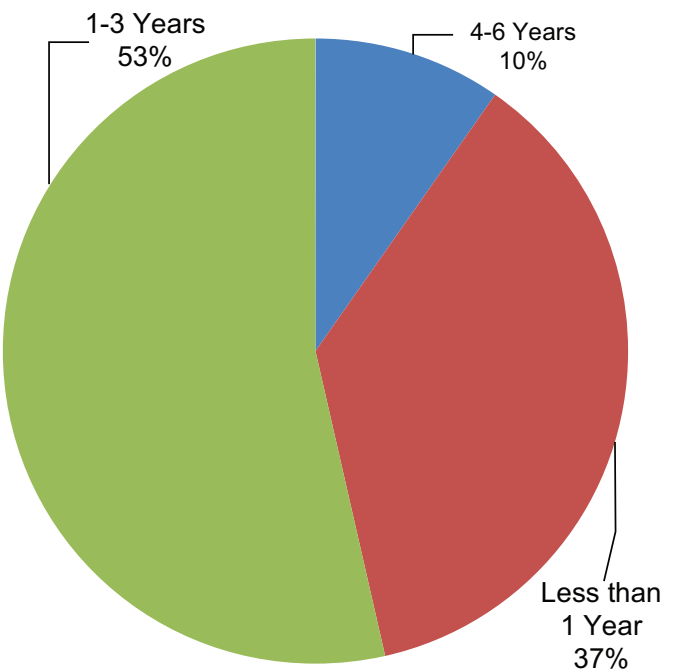

Fig -1: pie diagram showing duration of symptoms in patients with abnormal uterine bleeding

Table-IV

Distribution of study subjects according to PALMCOEIN classification $(n=100)$

\begin{tabular}{lcc}
\hline AUB classification & No of patients & Percentage \\
\hline PALM $(\mathrm{n}=48)$ & & \\
AUB- $P$ & 5 & 5 \\
AUB- $A$ & 10 & 10 \\
AUB- $\mathrm{L}$ & 30 & 30 \\
AUB- $\mathrm{M}$ & 3 & 3 \\
COEIN $(\mathrm{n}=52)$ & & \\
AUB- $\mathrm{C}$ & Nill & 0 \\
AUB- $O$ & 44 & 44 \\
AUB- $\mathrm{E}$ & 7 & 7 \\
AUB- I (IUCD) & 1 & 1 \\
AUB- N & 0 & 0 \\
\hline
\end{tabular}

Table-V

Distribution of cases according to histopathological diagnosis $(n=100)$

\begin{tabular}{lcc}
\hline Diagnosis & Total cases $\mathrm{N}=100$ & Percentage \\
\hline PALM (63) & 6 & \\
AUB-P & 13 & 6 \\
AUB-A & 27 & 13 \\
AUB-L & 5 & 5 \\
AUB-A; L(adenomyosis & 57 \\
and leiomyoma) & & 12 \\
AUB-M(Malignancy and & 12 & \\
hyperplasia) & & \\
COEIN (37) & & 32 \\
AUB-O & 32 & 5 \\
AUB-E & 5 &
\end{tabular}

Table-VI

Correlation of clinical and histopathological diagnosis

\begin{tabular}{lcc}
\hline Category & $\begin{array}{c}\text { Clinical } \\
\text { PALM }(\mathrm{n}=48)\end{array}$ & $\begin{array}{c}\text { Histopathology } \\
\text { PALM }(\mathrm{n}=63)\end{array}$ \\
\hline AUB-P & 5 & 6 \\
AUB-A & 10 & 13 \\
AUB-L & 30 & 27 \\
AUB-A; & 0 & 5 \\
AUB-M & 3 & 12 \\
& COEIN(n=52) & COEIN $(\mathrm{n}=37)$ \\
AUB-O & 44 & 32 \\
AUB-E & 7 & 5 \\
AUB-I & 1 & 0 \\
\hline
\end{tabular}

Table-VII

Distribution of cases according to endometrial pattern on histopathology $(n=100)$

\begin{tabular}{lcc}
\hline & No of cases & Percentage \\
\hline Proliferative phase & 46 & 46 \\
Secretory phase & 32 & 32 \\
Endometrial hyperplasia & 11 & 11 \\
Endometrial carcinoma & 1 & 1 \\
Inflammatory & 1 & 1 \\
Atrophic & 4 & 4 \\
Endometrial and cervical polyp & 6 & 6 \\
\hline
\end{tabular}

\section{Discussion:}

Excessive blood loss interferes with a woman's physical, social and/ or marital quality of life ${ }^{14}$. Abnormal uterine bleeding can occur in pre, peri and post menopausal women. Most commonly AUB occur at the beginning and end of the reproductive life. Twenty percent of AUB occur in adolescents girls and more than $50 \%$ occurs in women older than forty five ${ }^{15}$. In our study $35 \%$ of patients belonged to 41 45 years age group, which corresponds with the study by Mitali $\mathrm{M}^{16}$.Multiparous women have a slightly more blood loss as compared to nulliparous ${ }^{17}$. In present series $38 \%$ patients had 5 or more pregnancies, which is nearly similar to other studies ${ }^{18}$.

Weight affects hormone production and overweight can cause $\mathrm{AUB}^{19}$. Obesity by increasing the overall life time exposure to oestrogen by peripheral aromatization of adrenal androgen increases the incidence of polyp, leiomyoma and endometrial carcinoma $^{20}$. In our study thirteen $(13 \%)$ patients were obese, ninety five percent patients were 
anaemic. Heavy menstrual bleeding is associated with low ferritin level ${ }^{21}$. In present study $14 \%$ patients were suffering from diabetes mellitus. Uncontrolled diabetes mellitus may cause anovulation by interfering with the hypothalamic-pituitary -ovarian axis $^{22}$.

In this study most common presenting symptom was menorrhagia(48\%) followed by metrorrhagia(25\%) and polymenorrhoea(22\%). This findings are consistent with other studies ${ }^{16}$. Rehana Khan et al found menorrhagia in $55.8 \%$, polymenorrhoea in $6.6 \%$ and menometrorrhagia in $6.6 \%$ cases $^{23}$.

In our study the most common cause of abnormal uterine bleeding was AUB-O(44\%), AUB $-L(30 \%)$ was the second common cause and third one was AUB-A $(10 \%)$. This study is in agreement with result of recent trials ${ }^{16}$. Yu Sun et al ${ }^{24}$ found AUB-O $(57.7 \%)$, AUB-P $(16.2 \%)$ as the second and AUB$L(12 \%)$ third common cause of AUB. This discripency is due to the incidence of endometrial polyp varies from 3.7 to $65 \% 25$ and the prevalence of adenomyosis vary widely, ranging from $5 \%$ to $70 \%{ }^{26}$.

Hysteroscopy and directed biopsy is the gold standard in the diagnosis of AUB, but still endometrial sampling is the most common practice in public hospitals. Among 100 patients $79(79 \%)$ cases underwent hysterectomy with or without $D$ and $C$ and $D$ and $C$ was done in $68 \%$ cases. Clinical findings were correlated with histopathology report. In AUB$O$ the clinical diagnosis correlate with histopathological findings in $72 \%$ cases( $44 \%$ vs. $32 \%)$. This closely resemble with other study ${ }^{27}$. Normal endomertium was found to be the commonest histopathological pattern with proliferative endometrium $46 \%$ and secretory endometrium $32 \%$. The findings were comparable with other studies ${ }^{16,28}$. Clinically diagnosed AUB-L was confirmed by histopathology in $90 \%$ cases $30 \%$ vs $27 \%$ ) and AUB-P in $100 \%$ cases. Which is in consistant with other study ${ }^{20}$. In present study histopathology identified higher number of AUB$\mathrm{A}(10 \% \mathrm{VS} .13 \%)$ than the clinical diagnosis. This findings correlate with other previous studies ${ }^{20,29}$. Clinical and histopathological diagnosis of a combination of AUB-A; L did not correlate( $0 \%$ vs. $5 \%$ ). This is due to the requirement to diagnose adenomyosis solely from specimen obtained at hysterectomy ${ }^{4}$. In histopathology endometrial hyperplasia was found in $11 \%$ and endometrial carcinoma in $1 \%$ cases. In AUB - $M$, the clinical and histopathological diagnosis was ( $3 \%$ vs. $12 \%)$ ). This disrepency is due to menstrual history is not specific for AUB-M. On bimanual examination uterus may be normal size and shape, as well as thickness of endometrium on ultasonograpgy depend on menstrual cycle .Similar observation was made by others also ${ }^{20}$. Atrophic endometrium in $4 \%$ and endometrial inflammation in $1 \%$ cases, which are in agreement with other studies ${ }^{31}$.

Patients with abnormal uterine bleeding for more than three months should be evaluated histologically. Histopathological examination of surgical specimen carries both diagnostic and therapeutic significance.

\section{Conclusion:}

AUB-O is the commonest cause of abnormal uterine bleeding. AUB-L is the most common cause of structural cause. The PALM-COEIN classification and histopathological diagnosis are complementary to each other.

\section{References:}

1. Saria T, Rashida B. Abnormal uterine bleeding. Patient management in Obstetrics and Gynaecology . 2019; $1^{\text {st }}$ edition: 286-97.

2. Kolhe S. Management of abnormal uterine bleeding-focus on ambulatory hysteroscopy . 2018;10: 127-36.

3. Emily Devis, Paul B, Sparzak.In: Stat Pearls (Internet). August 2019.

4. Munro M G, Critchley H.O, Fraser I.S for the FIGO Working Group on Menstrual Disorders. The FIGO classification of causes of abnormal uterine bleeding. Int J Gynecol Obstet. 2011; 113: 1-2.

5. Goodman A. Abnormal genital tract bleeding. Clin corner-stone. 2003; 3(I): 25-35.

6. Abnormal uterine bleeding. A Guide for patients. American Society for Reproductive Medicine. 2012.

7. Malcolm G Munro et al. FIGO classification system (PALM-COEIN) for causes of Abnormal Uterine Bleeding in nongravid women of reproductive age. International Journal of Gynecology and Obstetrics. 2011; 113(1): 3-13.

8. Goodman A. Abnormal genital tract bleeding . Clin Cornerstone. 2000; 3: 25-35. 
9. Hill D A. Abnormal uterine bleeding : avoid the rush to hysterectomy . J Fam Pract. 2009; 58(3): 136-42.

10. OGB Manag. Abnormal uterine bleeding: A Quick Guide To Evaluation And Treatment. 2002; 14(4):26-58.

11. Clark TJ ,Mann CH, Shah N, Khan KS, Song F, Gupta JK. Accuracy of out patient endometrial biopsy in the diagnosis of endometrial cancer: a systematic quantitive review. BJOG. 2002; 109(3): 313-21.

12. Marsh F, Kremer C, Duffy S. Delivering an effective out patient servicein gynaecology. A randomized controlled trial analysis the cost of out patient versus day care hysteroscopy. BJOG . 2004; 111(3): 243-48.

13. SobandeAA, Eskander M, Archibong El, Damole. Elective hysterectomy:Aclinicopathological review from Abha Catchment area of Soudia Arabia . west Afr J Med 2005;24: 31-5.

14. Heavy menstrual bleeding. NICE. Clinical Guideline . 2007;44.

15. Abnormal uterine bleeding. Jo Ann V, Pinkerton MD. University of Virginia Health System. Jan 2017.

16. Mitali Mhapatra, Pratima Mishra. Clinicopathological evaluation of Abnormal Uterine Bleeding. Journal of Health Research and Reviews in Developing Countries. 2015; 2: 45-9.

17. Khan S, Hammed S, Umber A. Histopathological pattern of endometrium on diagnostic $D$ and $C$ in patients with abnormal uterine bleeding. Annals KEMU. 2011;2: 166-170.

18. Kumar Suneet. Asian Journal of Biomedical and Pharmaceutical Sciences. 2016; 6(53): 50-1.

19. Abnormal uterine bleeding. American Academy of family physicians. May 2017.

20. Devanshi Mishra, Shabana Sultan. FIGO 's PALM-COEIN Classification of Abnormal Uterine Bleeding: A Clinicohistopathological Correlation in Indian setting. J Obstet Gynaecol India. 2017; 67(2): 119-125.

21. Warner PE, Critchley $\mathrm{H} \mathrm{O}$, Lumsden M A, Compbell Brown M, Douglas A, Murry GD. Menorrhagia : measured blood loss, clinical features and outcome in women with heavy periods : a survey with follow-up data. Am J Obstet Gynecol. 2004; 190(5): 1216-23.

22. Diaz A, Loufer M A, Breech LL. Menstruation in girls and adolescents : using the menstrual cycle as a vital sign. American College of Obstetricians and Gynecologists Committee on Adolescents Health care. 2006; 118(5): 2245-50.

23. Rehana Khan, Rana K Sherwani, Safia Rana, Seema Hakim , Zeba J. Clinico-pathological patterns in women with dysfunctional uterine bleeding . Iran J Pathol. 2016; 11(1): 20-26.

24. Yu Sun, Yuzhu Wong, Wenpei B, Lele Mao, Jiaying Wen. Prevelance of abnormal uterine bleeding according to new FIGO classication in Chinese Women of reproductive are. Inc Medicine. Aug 2018; 97(31): 11457.

25. Dreisler E, Stampe Sorenses S, Isben P H et al. prevelance of endometrial polyp and abnormal uterine bleeding in Danish population aged 20-74years. Ultrasonography Obstet Gynecol . 2009; 33: 102-8.

26. Dueholm M. Transvaginal ultrasound for diagnosis of adenomyosis: a review. Best Pract Res Clin Obstet gynecol 2006; 20(4): 569-82.

27. Salma Parveen ,Asma A, Furrafk N, Azra S, Pattern of lesion in hysterectomy specimen and clinical correlation. PJMHS Jan 2014;8(2):456.

28. Parvati Gorla, Sridevi S, Eswari D, Bhagya Lakshmi A, Manasa R. Histopathology of endometrium in abnormal uterine bleeding, in correlation with profile and ultasonogragic finding. I J M M S 2016;4(2).

29. C S Patil. A study of Clinical Correlation with Histopathological Diagnosis of Abnormal Uterine Bleeding. 2016;7(3):2348-2516.

30. Devi J, Aziz N. Histopathological pattern of endometrium in 500 cases of abnormal uterine bleeding in the age group of 50-66 years. Int $\mathrm{J}$ Med Sci Clin Invent . 2014;1(10): 579-85.

31. Kelekci S, Kaya E, Alan M, Alan Y, Bilge U, Mollamahmutoglu L. Comparison of transvaginal sonography, saline infusion sonography and office hysteroscopy in reproductive aged women with or without Abnormal Uterine Bleeding . Fertile Steril. 2005; 207(4): 259-65. 